\title{
Industrial robust yeast isolates with great potential for fermentation of lignocellulosic biomass
}

\author{
Francisco B. Pereira ${ }^{a}$, Aloia Romaní ${ }^{a}$, Héctor A. Ruiz ${ }^{b}$, José A. Teixeira ${ }^{a}$, Lucília Domingues ${ }^{a, *}$ \\ ${ }^{a}$ CEB - Centre of Biological Engineering, Universidade do Minho, Campus de Gualtar, 4710-057 Braga, Portugal \\ ${ }^{\mathrm{b}}$ Biorefinery and Food Engineering Laboratory, Food Research Department/School of Chemistry, Autonomous University of Coahuila, Blvd. V. Carranza e Ing. José Cárdenas \\ Valdés, 25280 Saltillo, Coahuila, Mexico
}

\section{H I G H L I G H T S}

- Industrial robust strains were screened for lignocellulosic ethanol production.

- Screen was conducted on a real hydrolysate from Eucalyptus globulus wood.

- The tolerance of the lignocellulose hydrolysate was highly variable among strains.

- A correlation between final ethanol titer and furfural detoxification was found.

- Distilleries showed to be a remarkable yeast source for lignocellulose fermentation.

\section{A R T I C L E I N F O}

\section{Article history:}

Received 31 January 2014

Received in revised form 6 March 2014

Accepted 8 March 2014

Available online 20 March 2014

\section{Keywords:}

Bio-ethanol

Inhibitor kinetics

Lignocellulose fermentation

PE-2

Pre-treatment

\begin{abstract}
A B S T R A C T
The search of robust microorganisms is essential to design sustainable processes of second generation bioethanol. Yeast strains isolated from industrial environments are generally recognised to present an increased stress tolerance but no specific information is available on their tolerance towards inhibitors that come from the pretreatment of lignocellulosic materials. In this work, a strategy for the selection of different yeasts using hydrothermal hydrolysate from Eucalyptus globulus wood, containing different concentrations of inhibitors, was developed. Ten Saccharomyces cerevisiae and four Kluyveromyces marxianus strains isolated from industrial environments and four laboratory background strains were evaluated. Interestingly, a correlation between final ethanol titer and percentage of furfural detoxification was observed. The results presented here highlight industrial distillery environments as a remarkable source of efficient yeast strains for lignocellulosic fermentation processes. Selected strains were able to resourcefully degrade furfural and HMF inhibitors, producing $0.8 \mathrm{~g}$ ethanol/Lh corresponding to $94 \%$ of the theoretical yield.
\end{abstract}

(ㄷ) 2014 Elsevier Ltd. All rights reserved.

\section{Introduction}

Lignocellulose raw materials derived from agricultural, industrial and forest sources can provide environmental, economic and strategic benefits, not competing with food production, when used as sustainable feedstock in a biorefinery context (Ruiz et al., 2013). An example of these feedstocks is Eucalyptus globulus wood residues, such as bark, cross-cut ends and wood chips resulted from kraft pulping processing, being that large amounts are currently being burned for electricity or heat production (Moshkelani et al.,

\footnotetext{
* Corresponding author. Tel.: +351 253604402.

E-mail addresses: franciscopereira@deb.uminho.pt (F.B. Pereira), aloia@ceb. uminho.pt (A. Romaní), hector_ruiz_leza@uadec.edu.mx (H.A. Ruiz), jateixeira@ deb.uminho.pt (J.A. Teixeira), luciliad@deb.uminho.pt (L. Domingues).
}

2013). Therefore, a promising strategy for the valorisation of these residues could be its utilization as main feedstock for the production of bioethanol and other value-added products by incorporating a biorefinery unit in an operating paper industry (Mussatto et al., 2010; Phillips et al., 2013).

Bioethanol from lignocellulose materials or also called second generation bioethanol is obtained by following main steps: (i) pretreatment of lignocellulose biomass (ii) saccharification of cellulose and (iii) fermentation of glucose. The pretreatment is carried out to alter its recalcitrant structure (formed by hemicellulose, cellulose and lignin) and to improve the enzymatic accessibility towards cellulose. In this context, the hydrothermal treatment or autohydrolysis is an environmentally-friendly treatment that follows the biorefinery concept (Ruiz et al., 2013). The hydrothermal treatment allows obtaining a solid phase composed by cellulose 
and lignin and solubilising the hemicellulose fraction into hemicellulose-derived compounds (mainly oligo- and mono-saccharides) (Garrote et al., 2008). Nevertheless, with the hardness of pretreatment, some degradation products of both sugars and lignin are released in liquid hemicellulosic phase. These can be grouped around three main classes, weak acids, furans and phenolics compounds. While acetic acid, the most common weak acid derived from lignocellulosic hydrolysates, is formed by deacetylation of hemicelluloses, furan compounds, 2-furaldehyde (furfural) and 5-hydroxymethyl-2-furaldehyde (HMF), are formed by dehydration of pentoses and hexoses, respectively (Pereira et al., 2011a). These degradation compounds are considered potent inhibitors of yeast growth and induce a harsh effect on yeast machinery reducing the ethanol yield and productivity (Modig et al., 2008). The presence of inhibitor compounds generated during the treatment is one of the major challenges faced in commercial production of lignocellulosic bioethanol (Palmqvist and Hanhn-Hägerdal, 2000).

One approach to tackle the inhibitor challenge is by using natural robust yeast strains. Industrial isolates are known to be very robust, show higher fermentation capacity (Mussatto et al., 2010; Pereira et al., 2010) and stress tolerance that is developed in presence of stress factors related with harsh industrial processes such as: high sugar and ethanol concentrations, elevated temperatures, $\mathrm{pH}$ variations and presence of toxic compounds (Pereira et al., 2011b; Della-Bianca et al., 2013). The microflora of traditional and industrial fermentation processes constitutes a potential source of microbial natural isolates that exhibit at least some of the desired physiological background characteristics for lignocellulosic fermentation even if they have not been traditionally exposed to these particular inhibitors. Some strains of Saccharomyces cerevisiae isolated from Brazilian sugarcane-to-ethanol distilleries ("cachaça" and bio-ethanol plants) have shown high fermentation efficiency with prolonged persistence in the fermentation system (Basso et al., 2008; Pereira et al., 2010, 2011b, 2012). Also, a flocculating strain isolated from a Swedish second generation bioethanol plant showed high tolerance to ethanol, osmotic stress and inhibitor presence (Westman et al., 2012). On the other hand, the evaluation of industrial strains as Kluyveromyces marxianus can be interesting since these yeasts are able to work at elevated temperatures and ferment glucose and xylose (Fonseca et al., 2008), desirable properties for a cost-efficient process. Moreover, the environmental conditions of stress are related with the expression of flocculent character of some laboratory strains. This characteristic could be helpful for lignocellulosic ethanol production (Landaeta et al., 2013). Despite being potential candidates to overcome the stressful conditions imposed to yeast cells in lignocellulosic fermentation processes and thus to drive this technology further, the use and characterization of these isolates in lignocellulosic fermentations has not been reported.

In order to select a promising yeast strain for lignocellulosic fermentation we conducted in this study a screening comprising ten $S$. cerevisiae and four $K$. marxianus strains isolated from harsh industrial environments and four laboratory background strains. For a more dose-to-reality approach, the inhibitor tolerance and fermentation performance was evaluated using a real hydrolysate from hydrothermally pretreated E. globulus wood (containing inhibitory compounds).

\section{Methods}

\subsection{Yeasts}

The strains tested in this work included ten industrial S. cerevisiae strains: three isolated from Brazilian bio-ethanol production plants - PE-2, CAT-1, VR-1 (Basso et al., 2008); one flocculating yeast strain isolated from a Swedish second generation bio-ethanol plant - CCUG53310 (Purwadi et al., 2007); five belonging to the UFLA collection (Federal University of Lavras, Brazil) isolated from Brazilian "cachaça" fermentation processes - CA11, CA1162, CA1185, CA1187, CA155 (Pereira et al., 2010) and one industrial S. cerevisiae strain isolated from a beer plant (Portugal) - 1762 BELG. Four industrial K. marxianus strains isolated from "cocoa" fermentations (Brazil) - $\mathrm{CH} 2-2$, CH9-1, CH8-1 and CH1-1 (Pereira et al., 1999). The set of S. cerevisiae laboratory strains (routinely used in research laboratory) included CEN.PK 113-7D (Pereira et al., 2010), NRRL Y-265 (Hojo et al., 1999) and an adapted laboratory strain of the flocculating yeast NRRL Y-265-ADAPT (Landaeta et al., 2013). For comparative propose, the K. marxianus CBS 6556 laboratory background strain was also included (Ribeiro et al., 2007). Stock cultures were maintained on YPD [1\% (w/v) yeast extract, $2 \%(\mathrm{w} / \mathrm{v})$ bacto-peptone and $2 \%(\mathrm{w} / \mathrm{v})$ glucose] agar plates at $4{ }^{\circ} \mathrm{C}$.

\subsection{Preparation of E. globulus wood (EGW) hydrothermal hydrolysate}

The chips of E. globulus wood (kindly provided by pulp mill ENCE, Pontevedra, Spain) were milled to pass an $8 \mathrm{~mm}$ screen, air-dried, homogenized and stored until use. The raw material was then assayed for composition (see Table 1) according to Romaní et al. (2010). The hydrothermal treatment was carried out following the procedure described by Romaní et al. (2010). Briefly, the EGW was mixed with water at a Liquid Solid Ratio $(\mathrm{LSR})=8 \mathrm{~kg} / \mathrm{kg}$ in a $3.75 \mathrm{~L}$ stainless steel reactor (Parr Instruments Company, Moline, IL). The treatment was performed at $150 \mathrm{rpm}$ and heated at desired maximal temperature $\left(T_{\max }\right)$ of $210^{\circ} \mathrm{C}$ in non-isothermal conditions, following the standard heating temperature-time profile (Garrote et al., 2008). The operational conditions of treatment were chosen on the basis of a previous work in which total saccharides released upon pretreatment achieved the maximum value (93.8\% of polysaccharide recovery) in the liquid and solid phases (Romaní et al., 2010). When the

\section{Table 1}

EGW characterization concerning raw material composition, solid yield and composition of solid pre-treated and hemicellulosic liquor phase (hydrolysate).

\begin{tabular}{ll}
\hline EGW composition & $\mathrm{g} / 100 \mathrm{~g}$ raw material, oven dry basis \\
\hline Glucan & $44.7 \pm 0.81$ \\
Xylan & $16.01 \pm 0.35$ \\
Arabinan & $1.09 \pm 0.05$ \\
Acetyl groups & $2.96 \pm 0.28$ \\
Klason lignin & $27.7 \pm 0.61$ \\
EGW pre-treatment & g/100 g raw material, oven dry basis \\
SY (solid yield) & 71.66 \\
NVC (non-volatile compounds) & 14.91 \\
Solid phase analysis & $\mathrm{g} / 100 \mathrm{~g}$ pre-treated solid \\
Glucan & $59.26 \pm 0.47$ \\
Xylan & $1.95 \pm 0.10$ \\
Arabinan & 0 \\
Acetil groups & $0.29 \pm 0.06$ \\
Klason lignin & $33.60 \pm 0.5$ \\
Liquid phase analysis & $\mathrm{g} / \mathrm{L}$ hemicellulosic liquor \\
Glucose & 0.64 \\
Xylose & 8.85 \\
Arabinose & 0.18 \\
Acetic acid & 3.11 \\
HMF & 0.33 \\
Furfural & 1.66 \\
Glucooligosaccharides & 1.15 \\
Xylooligosaccharides & 8.97 \\
Arabinooligosaccharides & 0 \\
Acetyl groups & 2.55 \\
Phenolic compounds & 2.01 \\
\hline
\end{tabular}

EGW pre-treatment: $T_{\max }=210^{\circ} \mathrm{C}$ or $S_{0}=4.08$. 
temperature was reached, the media were immediately cooled. The solid and liquid phases were separated by vacuum filtration. The hardness of treatment can be expressed as severity $\left(S_{0}\right)$, defined as follow (Lavoie et al., 2010):

$S_{0}=\log \left[\int_{0}^{t} \exp \left(\frac{T(t)-T_{\mathrm{REF}}}{\omega}\right) d t\right]$

where $T(\mathrm{t})$ stands for the time-temperature profile (including heating and cooling). Calculations were made assuming the values usually employed in literature $\left(T_{\mathrm{REF}}=100^{\circ} \mathrm{C}, \omega=14.75^{\circ} \mathrm{C}\right)$. After, the solid phase was recovered and washed with distilled water for solid yield (SY) determination. The composition of treated solid was analysed using the same methods as for raw material. An aliquot of liquid phase (hydrolysate) was filtered $(0.45 \mu \mathrm{m})$ and directly analysed by HPLC for monosaccharides (glucose, xylose and arabinose) and inhibitory compounds (acetic acid, furfural and HMF). A second aliquot was subjected to quantitative post-hydrolysis with $4 \%(\mathrm{w} / \mathrm{w})$ sulphuric acid $\left(121^{\circ} \mathrm{C}\right.$ and $20 \mathrm{~min}$ ) for oligosaccharides quantification. The post-hydrolysate was analyzed by HPLC. A third aliquot was dried at $105^{\circ} \mathrm{C}$ to constant weight for the non-volatile compounds (NVC). A resume of the liquid hemicellulosic liquor and pre-treated solid characterization is reported in Table 1.

Prior to its use for yeast growth, the hemicellulosic liquor was centrifuged for $10 \mathrm{~min}$ at $9000 \mathrm{rpm}\left(4^{\circ} \mathrm{C}\right)$ to remove the solid fraction, the $\mathrm{pH}$ was adjusted to $4.5(\mathrm{NaOH} 1 \mathrm{M})$ and then sterilized at $121^{\circ} \mathrm{C}$ for $20 \mathrm{~min}$. Afterward, the hemicellulosic liquor containing a residual glucose content $(<1 \mathrm{~g} / \mathrm{L})$ was supplemented with synthetic glucose to a final concentration of $114 \mathrm{~g} / \mathrm{L}$ allowing the comparison of the ethanol yields for all strains tested. The compounds present in the hydrolysate were diluted 1.42 times when the hydrolysate was supplemented with a concentrated solution of glucose resulting in a final concentration of inhibitors of furfural $1.1 \mathrm{~g} / \mathrm{L}, \mathrm{HMF} 0.2 \mathrm{~g} / \mathrm{L}$ and acetic acid $2.3 \mathrm{~g} / \mathrm{L}$.

\subsection{Fermentations}

The yeast for inoculation was grown in Erlenmeyer flasks filled with medium containing $50 \mathrm{~g} / \mathrm{L}$ glucose, $20 \mathrm{~g} / \mathrm{L}$ peptone and $10 \mathrm{~g} / \mathrm{L}$ yeast extract. After incubation at $30^{\circ} \mathrm{C}$ and $200 \mathrm{rpm}$ for $18-22 \mathrm{~h}$ (OD600 of 3-4), the cell suspension was aseptically collected by centrifugation $\left(10 \mathrm{~min}\right.$ at $7500 \mathrm{~g}, 4^{\circ} \mathrm{C}$ ) and resuspended in $1.5 \%$ $(\mathrm{w} / \mathrm{v}) \mathrm{NaCl}(\mathrm{pH} 3.0)$ to a concentration of $200 \mathrm{mg}$ fresh yeast $/ \mathrm{mL}$.

Shake-flask fermentations were performed in $100 \mathrm{~mL}$ Erlenmeyer flasks fitted with perforated rubber stoppers enclosing glycerol-locks (to permit $\mathrm{CO}_{2}$ exhaustion while avoiding the entrance of air) and incubated at $30{ }^{\circ} \mathrm{C}$ with $150 \mathrm{rpm}$ orbital agitation. Before pitching, the fermentation medium was aerated by stirring with a magnetic bar (length of $3 \mathrm{~cm}$ ) at $>850 \mathrm{rpm}$ for 20 min before inoculation, to achieve an oxygen concentration of $>95 \%$ saturation. Then, yeast cells were pitched at about $30 \times 10^{6}$ cells/mL into $30 \mathrm{~mL}$ of hydrolysate medium to start the fermentation. The fermentation evolution was monitored by mass loss and samples for analyses were taken just at the ending point.

Bioreactor fermentation of selected strain was performed in a 2-L stirred tank bioreactor (Autoclavable Benchtop Fermenter Type R'ALF, Bioengineering AG, Wald, Switzerland) containing $1 \mathrm{~L}$ of hydrolysate medium inoculated with $5 \mathrm{mg}$ fresh yeast $/ \mathrm{mL}$. After total oxygen consumption by yeast (until $1 \mathrm{~h}$ of fermentation), the oxygen concentration into the reactor was maintained at $0 \mathrm{~g} / \mathrm{L}$ under a continuous nitrogen flow. The fermentation run was performed at $30^{\circ} \mathrm{C}$ and $150 \mathrm{rpm}$. Several samples were taken at different points in time to evaluate glucose, glycerol, ethanol and inhibitor kinetics profiles.

\subsection{Analytical procedures}

The concentrations of glucose, xylose, arabinose, glycerol, ethanol, acetic acid, furfural and HMF in the EGW hydrolysate prepared as described above, were quantified by high performance liquid chromatography (HPLC). Glucose, xylose, arabinose, glycerol, ethanol and acetic acid were quantified upon separation of an aliquot of the hydrolysate in a Varian MetaCarb $87 \mathrm{H}$ column, eluted at $60^{\circ} \mathrm{C}$ with $0.005 \mathrm{M}$ sulfuric acid, at a flow rate of $0.7 \mathrm{~mL} / \mathrm{min}$. The peaks corresponding to glucose, xylose, arabinose, glycerol and ethanol were detected using a refractive index detector, whereas acetic acid, furfural and HMF were detected using an UV detector set at $210 \mathrm{~nm}$. Total phenolic compounds in hydrolysate and fermentation media were determined by absorbance readings (OD720), of the complex formed with the Folin-Ciocalteu reagent, as described in Conde et al. (2011). A standard curve with caffeic acid was used to determine the concentration of phenolic compounds, expressed as caffeic equivalents.

\subsection{Determination of fermentation parameters}

Ethanol conversion (EC) yield was calculated by the ratio between the final ethanol concentration produced $\left(\mathrm{E}_{\text {final }}\right)$ and the glucose consumed (difference between the initial $\left(G_{\text {initial }}\right)$ and residual glucose $\left(\mathrm{G}_{\text {residual }}\right)$ concentrations). It was expressed as a percentage $(\%)$ of the theoretical conversion yield, i.e. the yield considering a production of $0.511 \mathrm{~g}$ of ethanol per $\mathrm{g}$ of glucose. Ethanol productivity $(\mathrm{Qp}, \mathrm{g} / \mathrm{Lh}$ ) was defined as the ratio between final ethanol concentration $\left(\mathrm{E}_{\mathrm{final}}\right)$ and total fermentation time (fermentation was considered to be complete when the weight of the flasks stabilized, $\mathrm{t}_{\text {final }}$ ).

$$
\begin{aligned}
& E C=\frac{E_{\text {final }}}{\left(G_{\text {initial }}-G_{\text {residual }}\right) \cdot 0.511} \cdot 100 \\
& Q p=\frac{E_{\text {final }}}{t_{\text {final }}}
\end{aligned}
$$

\section{Results and discussion}

\subsection{Fermentation performance in hydrolysate medium}

Using an inhibitory E. globulus wood (EGW) hydrolysate (furfural $1.1 \mathrm{~g} / \mathrm{L}$, HMF $0.2 \mathrm{~g} / \mathrm{L}$ and acetic acid $2.3 \mathrm{~g} / \mathrm{L}$ ) as fermentation medium, the inhibitor tolerance and fermentation performance of 14 strains isolated from different industrial fermentation environments and four laboratory background strains were investigated. Fig. 1 shows the time-course of $\mathrm{CO}_{2}$ production (mass loss) for the 18 strains tested. These profiles allowed the evaluation of fermentation evolution since, under the oxygen-limiting conditions used in this study, the patterns of $\mathrm{CO}_{2}$ and ethanol production are closely related, because most $\mathrm{CO}_{2}$ originates from the fermentative pathway. The final ethanol and residual glucose concentrations attained by each strain as well as their batch ethanol productivity and ethanol conversion yield are shown in Table 2.

Analyzing the results from $\mathrm{CO}_{2}$ production profiles (Fig. 1) and kinetic fermentation parameters (Table 2), S. cerevisiae strains isolated from sugarcane-to-ethanol distilleries (bio-ethanol and "cachaça") presented a good fermentation performance in EGW hydrolysate, while the others industrial $K$. marxianus isolates and, mainly, the laboratory background strains were strongly inhibited in the fermentation medium. PE-2 strain, isolated from a Brazilian bio-ethanol production plant, showed the better $\mathrm{CO}_{2}$ production profile (faster fermentation rate) attaining a final ethanol concentration of $55 \mathrm{~g} / \mathrm{L}$, with fermentation reaching completion in less 


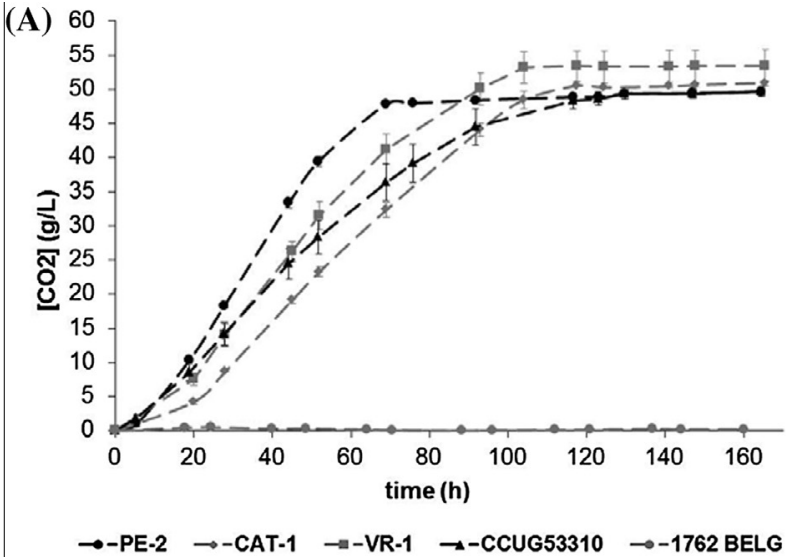

(B)

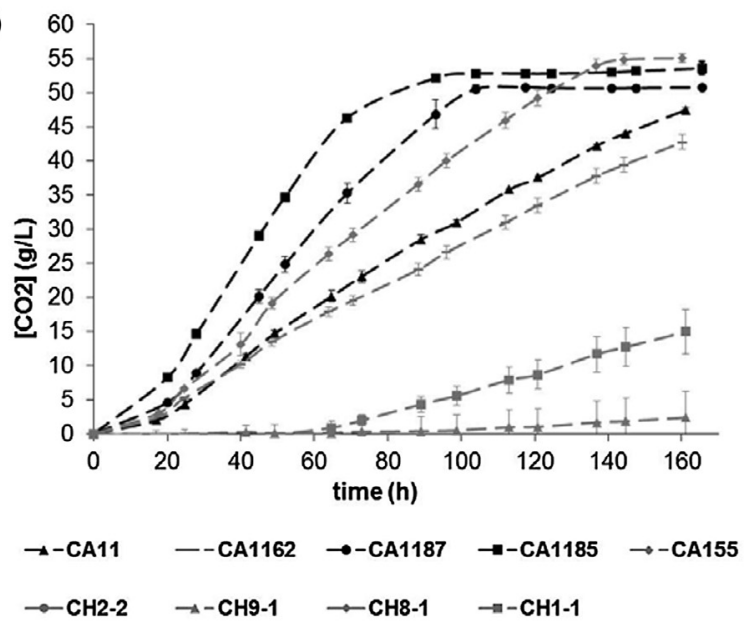

(C)

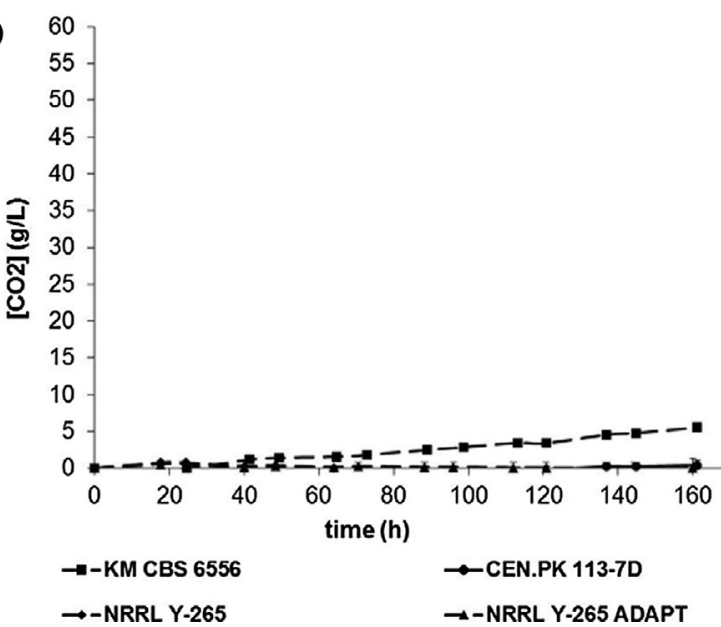

Fig. 1. Profiles of $\mathrm{CO}_{2}$ production obtained in EGW hydrolysate fermentations with ca. $114 \mathrm{~g} / \mathrm{L}$ glucose: (A) industrial strains isolated from first generation bio-ethanol (PE-2, VR-1 and CAT-1), second generation bioethanol (CCUG53310) and beer (1762 BELG) plants; (B) industrial strains isolated from Brazilian "cachaça" (CA11, CA155, CA1162, CA1187, CA1185) and cocoa fermentations (CH2-2, CH9-1, CH8-1 and CH1-1); (C) laboratory background strains (K. marxianus CBS 6556, CEN.PK 113-7D, NRRL Y-265 ADAPT and NRRL Y-265).

than $70 \mathrm{~h}$. The fermentation behavior of CAT-1 (isolated also from a Brazilian bio-ethanol distillery) and CCUG53310 (isolated from a Swedish second generation bio-ethanol plant) were similar, with fermentation being slightly slower (Fig. 1A). Fermentation by strain VR-1 (also isolated from a Brazilian bio-ethanol distillery) was much slower taking over $120 \mathrm{~h}$ to reach completion, but as can be seen in Table 2, the final ethanol titre reached was similar 53-54 g/L. These four industrial isolates were able to completely consume initial glucose concentrations close to $114 \mathrm{~g} / \mathrm{L}$ (Table 2), with ethanol yields between $92 \%$ and $94 \%$ of the theoretical (Table 2). The fermentation ability of these isolates can be differentiated analysing their values of batch ethanol productivity (Table 2). In this case, the PE-2 isolate showed a faster rate of sugar utilization than the other industrial isolates presenting ethanol productivity close to $0.8 \mathrm{~g} /$ Lh (Table 2 ), which was 1.6 -fold higher in comparison to VR-1, CAT-1 and CCUG53310 yeast strains. Contrarily to the strains isolated from bio-ethanol plants, 1762 BELG strain (isolated from a Portuguese beer plant) was strongly inhibited when inoculated in toxic EGW hydrolysate, being unable to start the fermentation process even after $160 \mathrm{~h}$ (see Fig. 1A). Interestingly, this observation confirms that strains isolated from stressful industrial environments (such as Brazilian distilleries) are more prepared to cope with biomass fermentations related stresses, namely nutrient starvation, the absence of oxygen or the presence of inhibitory compounds in fermentation medium, comparing to strains isolated from less stressful environments as beer fermentation plants.

Among the strains isolated from "cachaça" and cocoa fermentations in Brazil, CA1185 converted the glucose to ethanol much faster than the other industrial isolates (see Fig. 1B). Moreover, this strain fermented all of the glucose (residual of $0.0 \mathrm{~g} / \mathrm{L}$ ) producing $51 \mathrm{~g} / \mathrm{L}$ of ethanol with a productivity of $0.53 \mathrm{~g} / \mathrm{Lh}$ (Table 2). The other industrial isolates such as CA11, CA155 and CA1187 produced an ethanol concentration between 50 and $53 \mathrm{~g} / \mathrm{L}$ with ethanol productivities between 0.31 and $0.49 \mathrm{~g} / \mathrm{Lh}$ and values of ethanol conversion yield in a range of $87-94 \%$ (Table 2). CA1162 strain showed the lowest fermentation performance corresponding to a batch productivity of $0.25 \mathrm{~g} / \mathrm{Lh}$, left a residual of $c a .18 \mathrm{~g} / \mathrm{L} \mathrm{of}$ glucose unfermented after $160 \mathrm{~h}$ and consequently produced only $41 \mathrm{~g} / \mathrm{L}$ ethanol (Fig. 1B; Table 2). Fermentations by K. marxianus isolates (isolated from Brazilian cocoa fermentation plants) such as $\mathrm{CH} 2-2$, $\mathrm{CH} 9-1, \mathrm{CH} 8-1$ and $\mathrm{CH} 1-1$ were much more slower comparing to the $\mathrm{CO}_{2}$ fermentation progress of the other abovereferred $S$. cerevisiae industrial strains (Fig. 1C). $\mathrm{CH} 2-2, \mathrm{CH}-1$ and CH8-1 isolates left a glucose residual over than $100 \mathrm{~g} / \mathrm{L}$ even after $160 \mathrm{~h}$ of fermentation, while the $\mathrm{CH} 1-1$ isolate showed the better fermentation performance attaining an ethanol concentration of $21 \mathrm{~g} / \mathrm{L}$ after $160 \mathrm{~h}$, which corresponds to an ethanol productivity of $0.13 \mathrm{~g} / \mathrm{Lh}$.

Fig. $1 \mathrm{C}$ illustrate the $\mathrm{CO}_{2}$ production profiles of laboratory background strains. All S. cerevisiae strains (CEN.PK 113-7D, NRRL Y-265 and NRRL Y-265 ADAPT) were strongly inhibited in this toxic EGW hydrolysate, being these strains unable to start the fermentation process even after 160 h. The K. marxianus CBS 6556 was capable to begin the fermentation (Fig. 1C) presenting a final ethanol concentration of $9 \mathrm{~g} / \mathrm{L}$ corresponding to an ethanol theoretical yield of $64 \%$. The fermentation behavior of this laboratory K. marxianus strain was similar to the industrial K. marxianus isolate CH1-1, with fermentation being slightly slower (Fig. 1) and attaining also a lower ethanol titer at the end of fermentation process (Table 2).

All together, our results showed the superior ability of the industrial $S$. cerevisiae strains isolated from industrial distilleries (bio-ethanol and "cachaça") to convert sugars into ethanol at a faster rate comparing to the $S$. cerevisiae beer strain and to the industrial K. marxianus isolates and laboratory background strains.

Interestingly, during several years, PE- 2 and CAT-1 isolates have shown highest dominance and persistence in Brazilian distilleries being widely adopted by the industry (Amorim et al., 2011). Also, PE-2 and CA1185 isolates were previously selected for very high gravity (VHG) batch fermentations based on their higher ethanol titer and productivity during a yeast screening (Pereira et al., 
Table 2

Kinetic parameters of the 18 strains tested in EGW fermentations. Values are average of independent biological replicates.

\begin{tabular}{|c|c|c|c|c|c|}
\hline Strain & Source/reference & Residual glucose (g/L) & Final ethanol $(\mathrm{g} / \mathrm{L})$ & Ethanol productivity (g/Lh) & Ethanol, \% of the theoretical yield \\
\hline \multicolumn{6}{|c|}{ Saccharomyces cerevisiae } \\
\hline PE-2 & Basso et al. (2008) & $0.1 \pm 0.1$ & $54.6 \pm 0.3$ & $0.78 \pm 0.01$ & $94 \pm 1$ \\
\hline VR-1 & & $0.0 \pm 0.0$ & $54.1 \pm 1.9$ & $0.52 \pm 0.02$ & $93 \pm 3$ \\
\hline CAT1 & & $0.0 \pm 0.0$ & $53.8 \pm 0.2$ & $0.49 \pm 0.00$ & $92 \pm 0$ \\
\hline CCUG53310 & Purwadi et al. (2007) & $0.0 \pm 0.0$ & $54.4 \pm 0.3$ & $0.49 \pm 0.00$ & $93 \pm 1$ \\
\hline CA11 & Pereira et al. (2010) & $8.9 \pm 1.2$ & $50.8 \pm 2.6$ & $0.31 \pm 0.02$ & $94 \pm 4$ \\
\hline CA155 & & $0.1 \pm 0.0$ & $53.1 \pm 0.4$ & $0.37 \pm 0.00$ & $91 \pm 1$ \\
\hline CA1162 & & $17.6 \pm 0.4$ & $41.1 \pm 0.1$ & $0.25 \pm 0.00$ & $83 \pm 1$ \\
\hline CA1187 & & $0.0 \pm 0.0$ & $50.9 \pm 2.0$ & $0.49 \pm 0.02$ & $87 \pm 3$ \\
\hline CA1185 & & $0.0 \pm 0.0$ & $51.3 \pm 0.4$ & $0.53 \pm 0.00$ & $88 \pm 1$ \\
\hline 1762 BELG & Portuguese beer plant & $104.0 \pm 1.7$ & $0.9 \pm 0.1$ & $0.01 \pm 0.00$ & $18 \pm 1$ \\
\hline CEN.PK 113-7D & Pereira et al. (2010) & $86.8 \pm 6.9$ & $0.7 \pm 0.1$ & $0.00 \pm 0.00$ & $5 \pm 0$ \\
\hline NRRL Y-265 & Hojo et al. (1999) & $103.9 \pm 0.4$ & $2.0 \pm 0.6$ & $0.01 \pm 0.00$ & $39 \pm 9$ \\
\hline NRRL Y-265 ADAPT & Landaeta et al. (2013) & $107.7 \pm 0.6$ & $0.9 \pm 0.1$ & $0.01 \pm 0.00$ & $28 \pm 1$ \\
\hline \multicolumn{6}{|c|}{ Kluyveromyces marxianus } \\
\hline $\mathrm{CH} 2-2$ & Pereira et al. (1999) & $107.9 \pm 1.6$ & $2.3 \pm 0.8$ & $0.01 \pm 0.01$ & $73 \pm 7$ \\
\hline CH9-1 & & $103.2 \pm 1.7$ & $0.2 \pm 0.2$ & $0.00 \pm 0.00$ & $3 \pm 3$ \\
\hline CH8-1 & & $108.2 \pm 1.2$ & $0.2 \pm 0.2$ & $0.00 \pm 0.00$ & $9 \pm 8$ \\
\hline $\mathrm{CH} 1-1$ & & $68.5 \pm 4.2$ & $21.0 \pm 2.6$ & $0.13 \pm 0.02$ & $90 \pm 3$ \\
\hline CBS 6556 & Ribeiro et al. (2007) & $87.1 \pm 0.6$ & $8.9 \pm 0.9$ & $0.05 \pm 0.01$ & $64 \pm 8$ \\
\hline
\end{tabular}

2010). Moreover, their robust physiological background under these intensified fermentation conditions was characterized, both demonstrating an improved accumulation of trehalose, glycogen and sterols relatively to CEN.PK 113-7D laboratory strain (Pereira et al., 2011b). In spite of the previous demonstrated robustness of these isolates its fermentation performance in a medium to which these yeasts were not adapted, is remarkable.

Previous studies have investigated the performance of various laboratory background strains (Modig et al., 2008), metabolic recombinant strains (Hawkins and Doran-Peterson, 2011) and commercially available industrial strains (Brandberg et al., 2004; Kasavi et al., 2012) and high heterogeneity among the tested strains was also found. Brandberg et al. (2004) studied different strains of $S$. cerevisiae (seven different commercially available industrial strains, one CBS 8066 laboratory strain and one ATCC 96581 strain isolated from spent sulphite liquor at Swedish pulp plant) and found differences among strains of $45 \%$ less ethanol production. The strain isolate from bioethanol plant was the most efficient producer of ethanol which is expectable as the strain was already adapted to the substrate. In other study, a set of $S$. cerevisiae strains (isolated from wines, grape marcs and beer), a robust industrial strain (MH100) and the type strain S. cerevisiae (DSM70449) were evaluated to ferment wheat bran hydrolysates (Favaro et al., 2013). Interestingly, these authors concluded that the $S$. cerevisiae MEL2 strain isolated from grape marcs showed a fermentative efficiency much higher than the industrial $S$. cerevisiae DSM70449, which has been used to produce ethanol from different lignocellulosic substrates.

\subsection{Inhibitory compounds in fermentation medium}

During the hydrothermal treatment, numerous compounds are generated, many of which inhibit microbial growth and metabolism, affecting the fermentation process (Palmqvist and Hahn-Hägerdal, 2000; Liu, 2006). Several works have reported that the synergist effect of inhibitory compounds is higher than the single inhibitory compound (Liu et al., 2004; Tian et al., 2009). Therefore, the final concentration of inhibitors (acetic acid, phenolic compounds, HMF and furfural) in fermentation medium was quantified and is shown in Fig. 2.

During the fermentations trials, acetic acid concentration in all set of experiments varied in the range $1.8-2.9 \mathrm{~g} / \mathrm{L}$ (average content of $2.5 \mathrm{~g} / \mathrm{L}$ ). The slight increase observed in most experiments (from initial concentration of $2.3 \pm 0.2 \mathrm{~g} / \mathrm{L}$ to maximal concentration of $2.9 \pm 0.03 \mathrm{~g} / \mathrm{L}$, see Fig. 2) can be due to a production of acetic acid during the fermentation process. Interestingly, HMF and furfural concentrations decreased (0.31-0 and $1.18-0 \mathrm{~g} / \mathrm{L}$, respectively) in fermentation assays carried out by "Brazilian bio-ethanol" and "cachaça" strains (Fig. 2A and B). Moreover, it was not observed a significant variation in the concentrations of phenolic compounds $(0.8-0.91 \mathrm{~g} / \mathrm{L})$ in most of strains, except NRRL Y265 and Y265-ADAP (0.5 g/L) (see Fig. 2C).

In the fermentations carried out by strains isolated from bioethanol plants, the final HMF concentration was in the range of $0.05-$ $0.11 \mathrm{~g} / \mathrm{L}$ (Fig. 2A). On the other hand, the strains isolated from Brazilian "cachaça" fermentation processes were able to degrade the HMF to concentrations lower than $0.06 \mathrm{~g} / \mathrm{L}$, except for CA11 $(0.19 \mathrm{~g} / \mathrm{L})$, see Fig. 2B. Among industrial K. marxanius strains, CH1-1 and K. marxianus CBS 6556 consumed the HMF, achieving a final concentration of $0.09 \mathrm{~g} / \mathrm{L}$. The laboratory strains and the isolated strain from beer plant were not able to metabolize the HMF. The studied strains degraded furfural (see Fig. 2A and B) in most of the experiments. However, the laboratory strains and $K$. marxanius (CH2-2, $\mathrm{CH} 9-1$ and $\mathrm{CH} 8-1$ ) showed a final furfural range of $0.38-$ $0.77 \mathrm{~g} / \mathrm{L}$ and $0.3-0.51 \mathrm{~g} / \mathrm{L}$, respectively (see Fig. $2 \mathrm{~B}$ and $\mathrm{C}$ ).

The improved ethanol fermentation performance of industrial background strains could be related with their higher capacity of furan degradation as can be observed in Fig. 3. During the lag phase of fermentation, inhibitory compounds derived from pretreatment step such as furfural, HMF and some phenolic derivatives can be detoxified by yeast cells (Almeida et al., 2009). Yeast strains are able to reduce the furfural and HMF to their corresponding alcohols, which are less inhibitory (Liu, 2011). However, as can be observed in Fig. 3, the rates for this reduction vary considerably between strains. In Fig. 3B, it can be observed that K. marxianus ( $\mathrm{CH} 2-2$, CH9-1 and CH8-1) and laboratory strains were not able to degrade $\mathrm{HMF}$, with exception of $\mathrm{CH} 1-1$. On the other hand, $\mathrm{PE}-2$ and CCUG53310 industrial strains obtained higher ethanol concentrations and productivities and present a full degradation of the furan compounds (see, Fig. 3). As general trend, strains isolated from Brazilian ethanol plant and "cachaça" fermentations showed higher detoxification percentage of furans and ethanol production than the laboratory background strains and K. marxianus yeasts. Brandberg et al. (2004) reported an efficient conversion of HMF by 
(A)

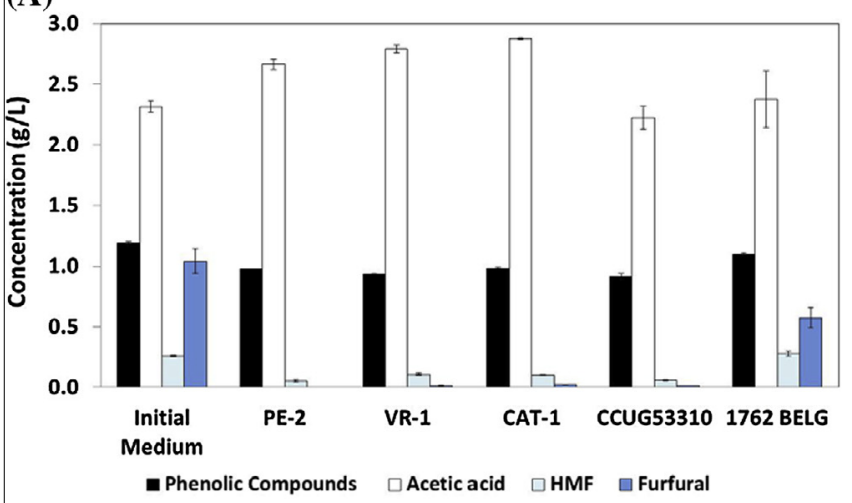

(B)

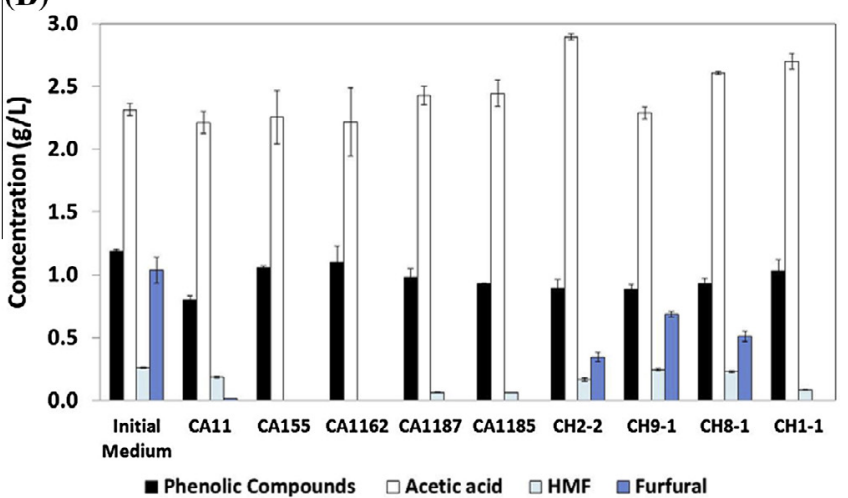

(C)

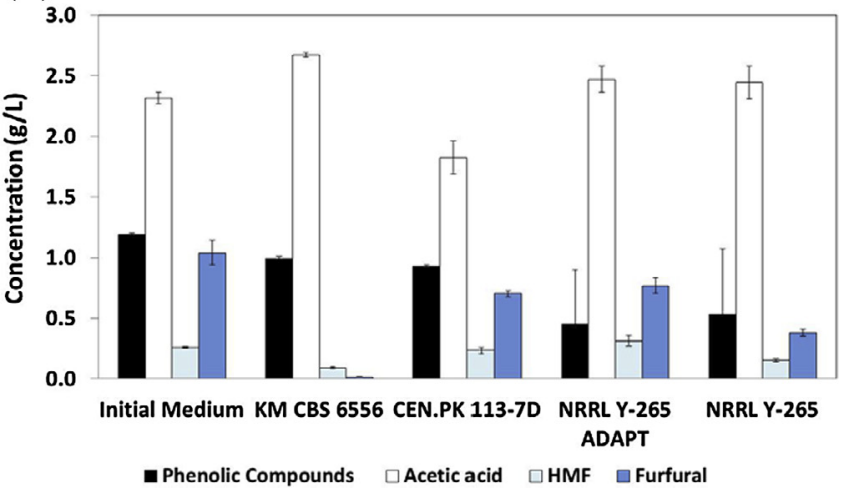

Fig. 2. Phenolic compounds, acetic acid, furfural and HMF concentration in the initial medium and at the end of EGW fermentations by (A) industrial strains isolated from first generation bio-ethanol (PE-2, VR-1 and CAT-1), second generation bio-ethanol (CCUG53310) and beer (1762 BELG) plants; (B) industrial strains isolated from Brazilian "cachaça" (CA11, CA155, CA1162, CA1187, CA1185) and cocoa fermentations (CH2-2, CH9-1, CH8-1 and $\mathrm{CH} 1-1)$; (C) laboratory background strains (K. marxianus CBS 6556, CEN.PK 113-7D, NRRL Y-265 ADAPT and NRRL Y-265).

isolated strain from spent sulphite liquor from Swedish pulp plant (ATCC 96581). In this case, the authors proposed that the same enzymes were involved in both process (ethanol production and furan conversion). The alcohol dehydrogenase may reduce the aldehyde group of furfural, therefore a high activity of alcohol dehydrogenase could benefit the conversion of furfural and the production of ethanol (Brandberg et al., 2004; Liu et al., 2004). Moreover, Westman et al. (2012) observed a higher HMF and furfural consumption by the flocculating strain (CCUG53310) in comparison with the laboratory strain (CBS8066). Interestingly, in the present work the strains isolated from Brazilian ethanol plants and "cachaça" fermentations were able to detoxify the furan compounds as the isolates from industrial 2nd generation ethanol plants.
(A)
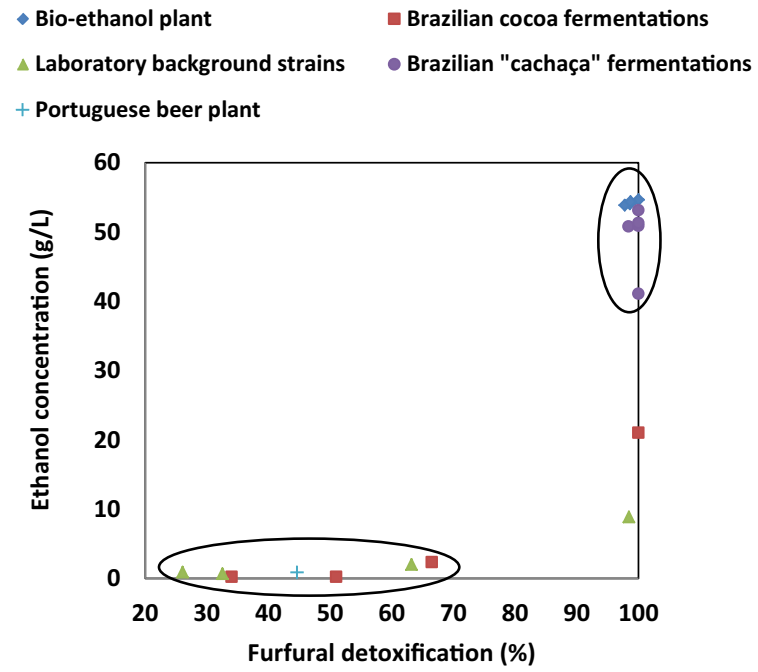

(B)
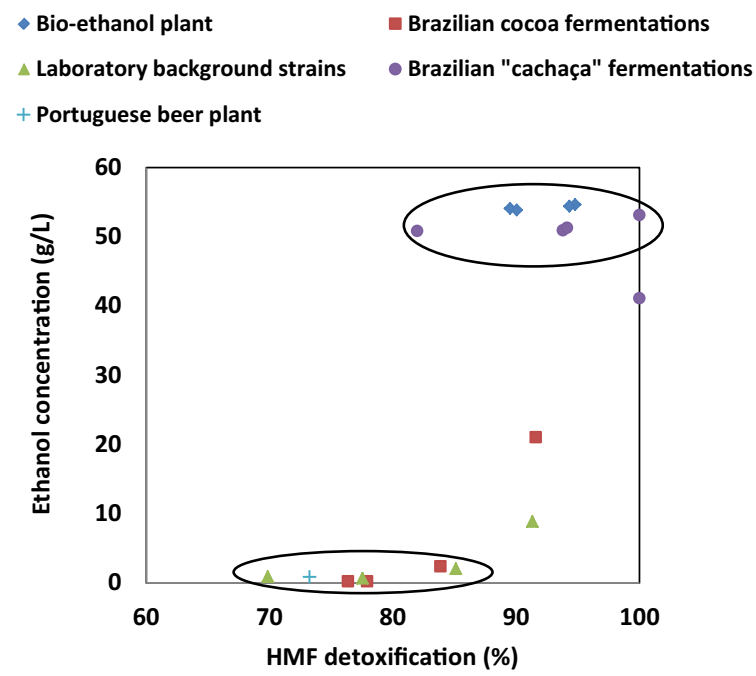

Fig. 3. Final ethanol concentration $(g / L)$ as a function of detoxification percentage (\%) of: (A) furfural; (B) HMF for different screened yeast strains.

\subsection{Furfural-HMF complex detoxification}

The presence of furfural and HMF in the fermentation medium has been associated with a negative influence on microbiology physiology, causing cell growth inhibition, decreasing ethanol productivity, DNA damaging and inhibiting of several enzymes participating in glycolysis (Almeida et al., 2009). Nevertheless, several studies show that the tolerance to inhibitory compounds depends on the microbial strain due to different features of cell membranes and metabolism (Klinke et al., 2004). On the basis of fermentation trials results (Table 2), the strains PE-2 and CCUG53310 were selected, since the fermentation parameters (EC and $Q p$ ) were the most promising. To further study the detoxification capacity of these strains, the furfural and HMF concentrations were measured during the fermentation (see Fig. 4). Fig. 4A shows the ethanol concentration and furfural degradation. Furfural was rapidly consumed and the maximum ethanol concentration was achieved at $65 \mathrm{~h}$ of fermentation. The main difference observed between the two strains was the furfural degradation. The PE- 2 was able to detoxify furfural content to $0.05 \mathrm{~g} / \mathrm{L}$ after $5 \mathrm{~h}$ (3.6-fold less time than CCUG53310). On Fig. 4A, it can also be seen that the lag phase was prolonged $(<5 \mathrm{~h})$ until the furfural was degraded. Using a 

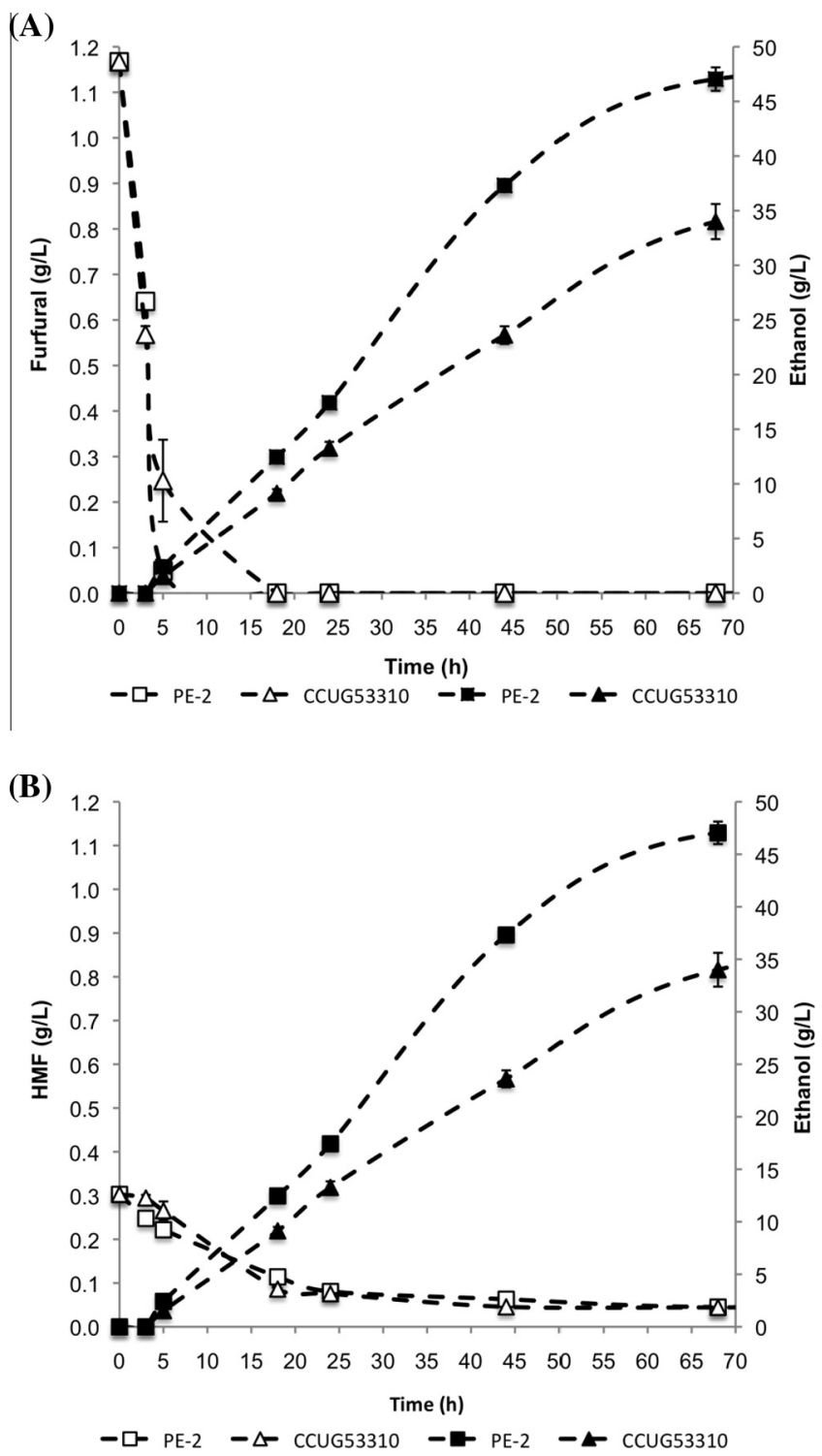

Fig. 4. Kinetics of bio-detoxification of EGW hydrolysate by the industrial $S$. cerevisiae strains PE-2 and CCUG53310. (A) Furfural degradation profile; (B) HMF degradation profile.

medium with $10 \mathrm{mM}$ furfural and HMF, an ethanologenic industrial S. cerevisiae (ATCC 211239) showed a lag phase of 8 and $4 \mathrm{~h}$, respectively (Liu et al., 2004). Tian et al. (2009) reported a lag phase of $4 \mathrm{~h}$ in a supplemented media with furfural and $\operatorname{HMF}(1 \mathrm{~g} / \mathrm{L})$, using strains developed in their laboratory and an increase of lag phase of $20 \mathrm{~h}$ with $4 \mathrm{~g} / \mathrm{L}$ of furfural and HMF. In these works, it was observed that furfural shows a higher inhibitory effect on yeast cells than HMF at the same concentrations (Liu et al., 2004; Tian et al., 2009).

Fig. 4B shows the HMF degradation (0.3-0.1 g/L) representing $67 \%$ of total conversion in $16 \mathrm{~h}$. The HMF degradation profiles were similar for both strains. These data are in agreement with the literature (Purwadi et al., 2007; Westman et al., 2012) that reported above $90 \%$ conversion of HMF and furfural.

The higher ability of PE-2 and CCUG533010 industrial isolates to consume sugar and produce ethanol using an inhibitory EGW hydrolysate as fermentation medium could be related to the higher tolerance and general robustness to fermentation-related stresses previously attributed to these industrial isolates (reviewed by Della-Bianca et al., 2013; Westman et al., 2012). The PE-2 is one of the ethanol producer strains that has showed a higher dominance in the stressful industrial environments (remarkable sources of robust yeast strains) and has been used as a reference industrial isolate (Della-Bianca et al., 2013). Several studies show its higher ethanol tolerance appropriate for very high gravity fermentation, achieving final ethanol concentrations $>19 \%(\mathrm{v} / \mathrm{v})$ and productivity $>2.5 \mathrm{~g} / \mathrm{Lh}$ in comparison with laboratory strains (CEN.PK 113-7D) (Pereira et al., 2010, 2011b).

On the other hand, Westman et al. (2012) showed the inhibitor tolerance of S. cerevisiae CCUG53310 when compared with the $S$. cerevisiae CBS8066. These authors characterized the strain CCUG53310 for successful application and optimization in an industrial bioethanol production. The flocculating strain was able to consume the furfural and HMF (decrease of 93\% and 99\%) while the laboratory strain (CBS8066) removed $10 \%$ and $67 \%$ of HMF and furfural, respectively. Consequently, the productivity of lignocellulosic hydrolysate fermentation is highly dependent of the microorganism tolerance to inhibitory compounds derived from biomass pretreatment step and its fermentation capacity in that toxic environment. Then, the choice of strain will be of utmost importance for overall process optimization.

\subsection{Batch ethanol production in a 2 L-reactor}

High tolerance to inhibitors of robust industrial strain is one of the main keys for bioethanol production from lignocellulosic materials (Liu, 2006). As showed above, PE-2 strain showed the best performance in terms of fermentation and degradation of furan compounds.

Once the ethanol fermentation was studied in Erlenmeyer flasks, a final fermentation was carried out in a $2 \mathrm{~L}$ batch reactor using the PE-2 strain, in order to confirm the results with a scaling up. Fig. 5 shows the fermentation profile (glucose consumption and ethanol production) as well as the degradation kinetics of furfural and HMF. The difference of ethanol concentration between the assays in Erlenmeyer flask and reactor (54 and $43 \mathrm{~g} / \mathrm{L}$, respectively) was due to a difference in initial available glucose concentration (114 and $85 \mathrm{~g} / \mathrm{L}$, respectively). The ethanol conversion (EC) was $98 \%$ and maximal productivity $(\mathrm{Qp}=0.78 \mathrm{~g} / \mathrm{Lh})$ was

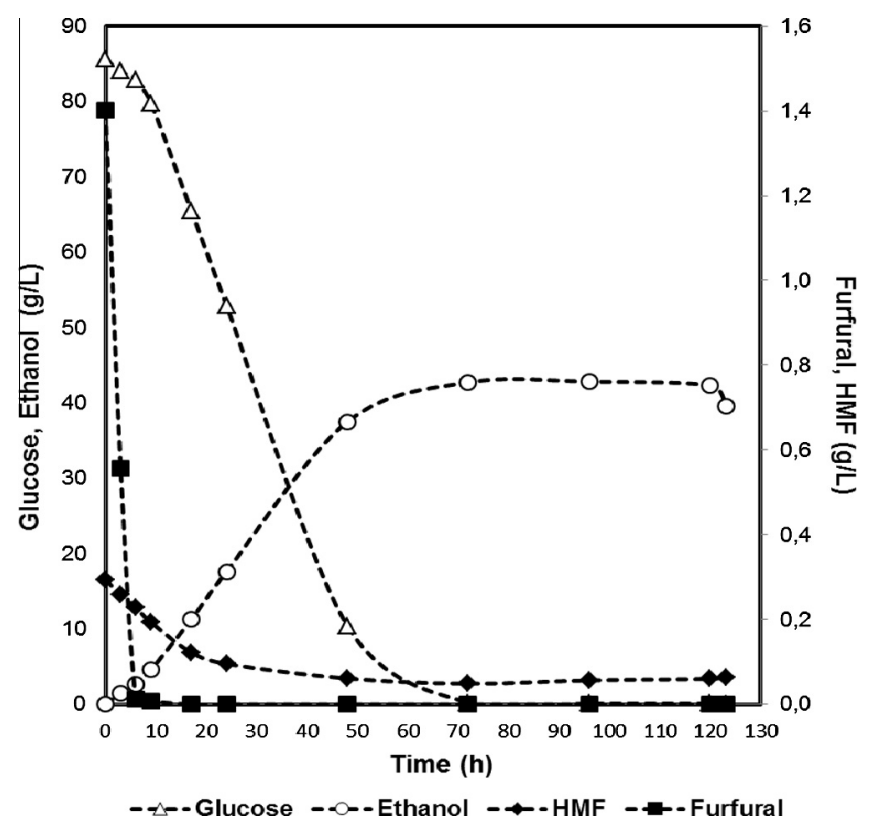

Fig. 5. Glucose, ethanol, furfural and HMF profiles during $2 \mathrm{~L}$ reactor fermentation by the industrial $S$. cerevisiae $\mathrm{PE}-2$ strain. 
achieved at $48 \mathrm{~h}$. The degradation of furans compounds was very similar to the one observed in the experiment conducted in Erlenmeyer flask (Fig. 4). Furfural was consumed in less of $6 \mathrm{~h}$ and the HMF content decreased to less of $67 \%$ in $24 \mathrm{~h}$. These results confirm a high reproducibility of ethanol production in batch reactor.

\section{Conclusions}

This work highlights the importance of strain selection for the application in lignocellulosic hydrolysates and demonstrates that the ability for furan compounds degradation is variable among yeast strains and determinant for efficient ethanol production from hydrolysates. Fermentation results showed the superior ability of the industrial $S$. cerevisiae strains isolated from industrial distilleries comparing to the industrial $K$. marxianus isolates, $S$. cerevisiae beer isolate and laboratory strains. Isolates PE-2 from 1 st generation bioethanol plant and CCUG53310 from 2nd generation bioethanol plant were the most efficient strains presenting a final ethanol concentration of $55 \mathrm{~g} / \mathrm{L}$ with the first showing higher ethanol productivity $(0.8 \mathrm{~g} / \mathrm{Lh})$.

\section{Acknowledgements}

The authors thank Rosane Schwan (Federal University of Lavras, Brazil) for kindly providing the yeast strains (isolated from Brazilian "cachaça" and "bio-ethanol" fermentations) and Juan Carlos Parajó and Gil Garrote (University of Vigo, Spain) for assistance in the pre-treatment of lignocellulose biomass. Research described in this article was financially supported by FEDER funds of EU and "Fundação para a Ciência e a Tecnologia" (FCT), Portugal: Contract PTDC/BIO/66151/2006, Strategic Project PEst-OE/EQB/LA0023/ 2013, Project "BioInd - Biotechnology and Bioengineering for improved Industrial and Agro-Food processes, REF. NORTE-07-0124FEDER-000028" Co-funded by the Programa Operacional Regional do Norte (ON.2 - O Novo Norte), QREN, FEDER and the PhD grant to FP and Pos-Doc grant to AR.

\section{References}

Almeida, J.R.M., Bertilsson, M., Gorwa-Grauslund, M.F., Gorsich, S., Lidén, G., 2009 Metabolic effects of furaldehydes and impacts on biotechnological process. Appl. Microbiol. Biotechnol. 82, 625-638.

Amorim, H.V., Lopes, M.L., De Castro Oliveira, J.V., Buckeridge, M.S., Goldman, G.H. 2011. Scientific challenges of bioethanol production in Brazil. Appl. Microbiol. Biotechnol. 91 (5), 1267-1275.

Basso, L.C., De Amorim, H.V., De Oliveira, A.J., Lopes, M.L., 2008. Yeast selection for fuel ethanol production in Brazil. FEMS Yeast Res. 8 (7), 1155-1163.

Brandberg, T., Franzén, C.J., Gustafsson, L., 2004. The fermentation performance of nine strains of Saccharomyces cerevisiae in batch and fed-batch cultures in dilute-acid wood hydrolysate. J. Biosci. Bioeng. 98 (2), 122-125.

Conde, E., Moure, A., Domínguez, H., Parajó, J.C., 2011. Production of antioxidants by non-isothermal autohydrolysis of lignocellulosic waste. LWT-Food Sci. Technol. 44 (2), 436-442.

Della-Bianca, B.E., Basso, T.O., Stambuk, B.U., Basso, L.C., Gombert, A.K., 2013. What do we know about the yeast strains from the Brazilian fuel ethanol industry? Appl. Microbiol. Biotechnol. 97 (3), 979-991.

Favaro, L., Basaglia, M., van Zyl, W.H., Casella, S., 2013. Using an efficient fermenting yeast enhances ethanol production from unfiltered wheat bran hydrolysates. Appl. Energy 102, 170-178.

Fonseca, G.G., Heinzle, E., Wittmann, C., Gombert, A.K., 2008. The yeast Kluyveromyces marxianus and its biotechnological potential. Appl. Microbiol. Biotechnol. 79, 339-354.

Garrote, G., Yáñez, R., Alonso, J.L., Parajó, J.C., 2008. Coproduction of oligosaccharides and glucose from corncobs by hydrothermanl processing and enzymatic hydrolysis. Ind. Eng. Chem. Res. 47, 1336-1345.
Hawkins, G.M., Doran-Peterson, J., 2011. A strain of Saccharomyces cerevisiae evolved for fermentation of lignocellulosic biomass displays improved growth and fermentative ability in high solids concentrations and in the presence of inhibitory compounds. Biotechnol. Biofuels 4, 49.

Hojo, O., Hokka, C.O., Maior, A.M.S., 1999. Ethanol production by a flocculant yeast strain in a CSTR type fermentor with cell recycling. Appl. Biochem. Biotechnol. 77-79, 535-546.

Kasavi, C., Finore, I., Lama, L., Nicolaus, B., Oliver, S.G., Toksoy Oner, E., Kirdar, B. 2012. Evaluation of industrial Saccharomyces cerevisiae strains for ethanol production from biomass. Biomass Bioenergy 45, 230-238.

Klinke, H.B., Thomsen, A.B., Ahring, B.K., 2004. Inhibition of ethanol-producing yeast and bacteria by degradation products produced during pre-treatment of biomass. Appl. Microbiol. Biotechnol. 66, 10-26.

Landaeta, R., Aroca, G., Acevedo, F., Teixeira, J.A., Mussatto, S.I., 2013. Adaptation of a flocculent Saccharomyces cerevisiae strain to lignocellulosic inhibitors by cell recycle batch fermentation. Appl. Energy 102, 124-130.

Lavoie, J.M., Capek-Menard, E., Gauvin, H., Chornet, E., 2010. Production of pulp from Salix viminalis energy crops using the FIRSST process. Bioresour. Technol. 101, 4940-4946.

Liu, Z.L., 2006. Genomic adaptation of ethanologenic yeast to biomass conversion inhibitors. Appl. Microbiol. Biotechnol. 73, 27-36.

Liu, Z.L., 2011. Molecular mechanisms of yeast tolerance and in situ detoxification of lignocellulose hydrolysates. Appl. Microbiol. Biotechnol. 90 (3), 809-825.

Liu, Z.L., Slininger, P.J., Dien, B.S., Berhow, M.A., Kurtzman, C.P., Gorsich, S.W., 2004. Adaptive response of yeast to furfural and 5-hydroxymethylfurfural and new chemical evidence for HMF conversion to 2,5-bis-hydroxymethylfuran. J. Ind. Microbiol. Biotechnol. 31, 345-352.

Modig, T., Almeida, J.R.M., Gorwa-Grauslund, M.F., Lindén, G., 2008. Variability of the response of Saccharomyces cerevisiae strains to lignocellulose hydrolysate. Biotechnol. Bioeng. 100 (3), 423-429.

Moshkelani, M., Marinova, M., Perrier, M., Paris, J., 2013. The forest biorefinery and its implementation in the pulp and paper industry: energy overview. Appl. Therm. Eng. 50 (2), 1427-1436.

Mussatto, S.I., Dragone, G., Guimarães, P.M.R., Silva, J.P.A., Carneiro, L.M., Roberto, I.C., Vicente, A., Domingues, L., Teixeira, J.A., 2010. Technological trends, global market, and challenges of bio-ethanol production. Biotechnol. Adv. 28 (6), 817 830.

Palmqvist, E., Hahn-Hägerdal, B., 2000. Fermentation of lignocellulosic hydrolysates. I: inhibition and detoxification. Bioresour. Technol. 74 (1), 17-24.

Pereira, F.B., Gomes, D.G., Guimarães, P.M.R., Teixiera, J.A., Domingues, L., 2012. Cell recycling during repeated very high gravity bio-ethanol fermentations using the industrial Saccharomyces cerevisiae strain PE-2. Biotechnol. Lett. 34 (1), 45-53.

Pereira, F.B., Guimarães, P.M.R., Gomes, D.G., Mira, N.P., Teixeira, M.C., Sá-Correia, I. Domingues, L., 2011a. Identification of candidate genes for yeast engineering to improve bioethanol production in very high gravity and lignocellulosic biomass industrial fermentation. Biotechnol. Biofuels 4, 57.

Pereira, F.B., Guimarães, P.M.R., Teixeira, J.A., Domingues, L., 2010. Selection of Saccharomyces cerevisiae strains for efficient very high gravity bio-ethanol fermentation processes. Biotechnol. Lett. 32 (11), 1655-1661.

Pereira, F.B., Guimarães, P.M.R., Teixeira, J.A., Domingues, L., 2011b. Robust industrial Saccharomyces cerevisiae strains for very high gravity bio-ethanol fermentations. J. Biosci. Bioeng. 112 (2), 130-136.

Pereira, M., Schwan, R., Teixeira, J., 1999. Isolation, screening and characterisation of flocculating and pectinase producing Kluyveromyces strains. Food Technol. Biotechnol. 37 (4), 257-261.

Phillips, R.B., Jameel, H., Chang, H.M., 2013. Integration of pulp and paper technology with bioethanol production. Biotechnol. Biofuels 6, 13 .

Purwadi, R., Brandberg, T., Taherzadeh, J.M., 2007. A possible industrial solution to ferment lignocellulosic hydrolyzate to ethanol: continuous cultivation with flocculating yeast. Int. J. Mol. Sci. 8, 920-932.

Ribeiro, O., Gombert, A.K., Teixeira, J.A., Domingues, L., 2007. Application of the CreloxP system for multiple gene disruption in the yeast Kluyveromyces marxianus. J. Biotechnol. 131, 20-26.

Romaní, A., Garrote, G., Alonso, J.L., Parajó, J.C., 2010. Bioethanol production from hydrothermally pretreated Eucalyptus globulus wood. Bioresour. Technol. 101 (22), 8706-8712.

Ruiz, H.A., Rodríguez-Jasso, R.M., Fernandes, B.D., Vicente, A.A., Teixeira, J.A., 2013. Hydrothermal processing, as an alternative for upgrading agriculture residues and marine biomass according to the biorefinery concept: A review. Renew. Sust. Energy Rev. 21, 35-51.

Tian, S., Zhou, G., Yan, F., Yu, Y., Yang, X., 2009. Yeast strains for ethanol production from lignocellulosic hydrolysate during in situ detoxification. Biotechnol. Adv. 27, 656-660.

Westman, J.O., Taherzadeh, M.J., Franzén, C.J., 2012. Inhibitor tolerance and flocculation of a yeast strain suitable for second generation bioethanol production. Electron. J. Biotechnol. 15 (3). 